\title{
Averted Lynching
}

\section{The Influence of Political Dynamics on Southern Lynch Mob Formation and Lethality}

\author{
Ryan Hagen, Kinga Makovi, and Peter Bearman, Columbia University
}

\begin{abstract}
-xisting literature focuses on economic competition as the primary causal factor - in Southern lynching. Political drivers have been neglected, as findings on their - effects have been inconclusive. We show that these consensus views arise from selection on a contingent outcome variable: whether mobs intent on lynching succeed. We constructed an inventory of averted lynching events in Georgia, Mississippi, and North Carolina-instances in which lynch mobs formed but were thwarted, primarily by law enforcement. We combined these with an inventory of lynching and analyzed them together to model the dynamics of mob formation, success, and intervention. We found that low Republican vote share is associated with a higher lethality rate for mobs. Lynching is better understood as embedded in a post-conflict political system, wherein all potential lynching events, passing through the prism of intervention, are split into successful and averted cases.
\end{abstract}

\section{Introduction}

In November 1905, the sheriff of Fulton County, Georgia, broke up a mob of white men intent on murdering Jim Walker, black, whom they accused of raping a prominent Atlanta woman. According to newspaper accounts the mob had already forced a noose around Walker's neck by the time the sheriff arrived and was able to push his way through the crowd. "Gentlemen, I beg you not to harm this prisoner," the sheriff told the mob after wrestling the rope from the hands of Walker's would-be lynchers. "I have promised that he shall be hanged, and it shall be done" (The Washington Post, 1905). The mob relinquished Walker into the sheriff's custody alive, though not before beating him so badly it was speculated he would not survive to stand trial.

A year earlier and one hundred miles to the northeast, John Ware, also black, had received no reprieve. Ware was arrested near Royston, Georgia, in the early afternoon on charges of murdering a white man with whom he had quarreled that morning. A mob quickly formed in pursuit of Ware, many of 
them churchgoers drawn out early from Sunday services, according to accounts. The mob intercepted Ware as the county sheriff was hurrying him to nearby Carnesville, Georgia, for safekeeping. Ware was taken from custody and hanged from a tree. His corpse was riddled with bullets and left suspended into the evening (Duluth News-Tribune, 1904).

Jim Walker recovered from his wounds sufficiently to be tried. He was convicted, sentenced to death, and executed by hanging under the auspices of the state less than a month after his rescue from the mob. For this reason, though Walker and Ware were both targets of lynch mobs and were both ultimately hanged to death in an atmosphere of mob violence, only Ware-and not Walker-is included among the 2,805 individuals in Beck and Tolnay's now-canonical inventory of lynching victims (Tolnay and Beck 1995a). In the sociological literature that flows from this data Walker's lynching, interrupted by a sheriff's intervention, is by design unobservable.

Ordeals like Walker's were not rare during this period. Southern lynch mobs were foiled nearly as often as they succeeded, according to contemporary estimates (Griffin 1993; Griffin et al. 1997). Using conservative criteria, we find that roughly one-third of lynching attempts were averted. Most often mob action was curtailed by law enforcement: sheriffs and militiamen successfully defended hundreds of people from mob violence either directly through force, or indirectly by spiriting them away to distant jails across county lines and out of the mobs' reach. Judges held expedited trials of suspects in an effort to preempt mob violence. In several cases governors personally intervened, mobilizing militia units or using the bully pulpit to persuade mobs to "let the law take its course." Occasionally lynch mobs voluntarily released their captives into law enforcement custody. Periodically, law-abiding citizens dissuaded mobs from their purpose on the grounds that the extralegal killing would dishonor their community. In the smallest fraction of cases, a man pursued or captured by a mob escaped or else committed suicide rather than suffer the torture of lynching. Even these suicides do not appear in existing lynching inventories.

All prior historical and sociological explanations have linked lynching to racial competition or stress in social, economic, or political life. While the specific arguments differ, they share a central element: a change in circumstances gives rise to white mobs that form to lynch black victims. This holds alike for accounts stressing the role of cotton market fluctuations in shifting incentives for whites (both poor and elite) to dominate the black population through lynching (Tolnay and Beck 1995a) and those emphasizing the role of struggles over citizenship rights (Blalock 1967).

Inquiries into the political context of lynching have focused, with some exceptions (see Inverarity 1976; Phillips 1987), on tests of Blalock's power threat hypothesis. This predicts that lynching will be associated with higher concentrations of the black population, since these concentrations would pose a greater political threat to the white establishment (Blalock 1967). Early findings that the pattern of lynching was harmonious with Blalock's hypothesis (Reed 1972; Corzine and Creech 1983) were overturned (Beck, Massey, and Tolnay 1989) and subsequently abandoned (Olzak 1990; Soule 1992; Tolnay and Beck 1995a). 
More recently the consensus has settled on economic competition as the primary driver of lynching, most notably Tolnay and Beck's work establishing a connection between lynching and the relative strength of the cotton economy (1995a). Here we consider whether our current understanding rests on the analysis of an artificially restricted set of these violent events.

The consensus that economic, not social and political, factors drove lynching is in many ways surprising. In a range of diverse settings inquiries into collective violence have found economic factors to be of limited explanatory power. Snyder and Tilly argued memorably that: "We do not think there is any general connection between collective violence and hardship.... The principal, immediate causes of collective violence are political: collective violence results from changes in the relations between groups of men and the major concentrations of coercive power in their environments" (Snyder and Tilly 1972; but see also Krueger and Pischke 1997; Green et al. 1998; Green, McFalls, and Smith 2001; Eitle, D'Allessio, and Stolzenberg 2002). While it is possible that Southern society from the period after Reconstruction to the years between the World Wars was an exception, this article suggests otherwise: that the economic focus has come at the expense of a fuller understanding of the social and political climate within which lynching occurred.

Southern racial violence significantly predates the period in which lynching became common. Indeed, Southern political resistance to Reconstruction often manifested itself in white-on-black violence that took hundreds of lives before the withdrawal of federal troops in 1877 (Kousser 1974; Ayers 1993). The epidemic of lynching that gripped the South between 1882 and 1930 is reasonably seen as a continuation of this violence as the postwar power realignment of the Redemption era was consummated. The Democratic Party had largely regained control of the state apparatus in the South by the 1880s, and once in power set out to permanently neutralize its opponents through the enactment of stringent voting restrictions constructed as a defense against the "threat of Negro Rule" (Redding 2003). As the Democratic Party consolidated its hold on the machinery of the state down to the county level, riding a wave of racial animus to which it had contributed, one should ask the question: how did it respond to the threat of lynching?

One possibility is that in areas of greatest Democratic political strength, interventions averting lynch mob activity were less frequent, in part because these areas will have embraced more fully the party's white supremacist platform. Conversely, in pockets where the Republican Party provided viable resistance to Democratic hegemony, successful lynching will have been less frequent, and averted lynching more frequent, as the local populations will have been less disposed to racial violence and local law enforcement officials would have been more likely to stand up to lynch mobs. These general patterns would be consistent with the fact that as blacks became increasingly marginalized and their status as citizens was increasingly degraded, they became more vulnerable to extralegal mob violence- a process repeatedly observed in a broad swath of comparative work demonstrating that the socially marginalized are more likely to be victims of collective violence in general (de la Roche 1996) and lynching specifically (Bailey et al. 2011). 
In short, we find unsatisfactory the consensus view that economic factors were the primary driver of lynching. In pursuit of new insight, we take seriously the idea, arising in a parallel line of research, that averted lynchings should be included in the analysis of collective violence in the South (Brundage 1993, 1994; Griffin 1993; Griffin et al. 1997; see also Ellis 1986). Averted and completed lynchings appear to be discretely different types of event, when selection is restricted to outcome. Yet archival evidence suggests that the success or failure of a potential lynching hinged overwhelmingly on a single contingency: the intervention or non-intervention of law enforcement. All potential lynching events can be seen as events of mob formation that share common roots and are subsequently sorted by a single contingency into one of two outcomes. If we seek an explanation of the drivers of lynching, then we need to recognize that the mechanisms at play are those that generate mobs (whether successful or not) and that generate intervention (whether successful or not).

This brief introduction identifies a selection problem that pervades the lynching literature. Analyses restricted to completed lynching events select on mob success, excluding a set of events, comparable in number and characteristics, in which violence was actively thwarted. Leaving averted lynching unobserved by design means selecting on lynch mob success, a strategy that limits our understanding of lynch mob genesis and the drivers of intervention. ${ }^{1}$

We start from the idea that lynching and averted lynching are parts of the same phenomenon, and should be considered as such. To arrive at a crisper picture of mob formation and collective violence in the American South, we constructed an inventory of averted and completed lynching incidents. Our inventory includes events in Georgia, Mississippi, and North Carolina between the years 1882 and 1930. We compared this data with the Beck-Tolnay inventory of completed lynching from the same states-about 800 events-to investigate the accuracy and possible biases of our inventory. This article engages the problem of lynch mob formation directly, rather than selecting only lynch mobs that succeeded in murdering their targets. By shifting focus, we provide new answers to three interlocking questions: Is the economic threat argument sufficient to explain mob formation? If not, what could have been the impact of the postReconstruction political environment on mob formation and intervention in mob violence? Finally, can solving the selection problem of unobserved averted lynching give us a better understanding of the phenomenon as a whole?

\section{Roadmap}

To address these puzzles, we first briefly establish some historical context. We then set out a working definition of averted lynching, outline the methodology used to construct our averted lynching inventory, and describe its contents. We next introduce a modeling strategy and report findings from analyses that consider the role economic, social, and political factors play in sorting mob formation events into lynching and averted lynching events. Finally, we discuss the implications of our findings for understanding the mechanisms that drove lynching in the South. 


\section{Historical Background}

As noted earlier, the broad consensus is that the fortunes of the cotton economy are central to understanding the dynamics of Southern race relations from Reconstruction to the Great Migration. We agree that the well-known economic context is salient. The political context, because less studied as it relates to lynching, is less well known. Consequently, a brief summary will be useful for the argument that follows. A decade after their defeat in the American Civil War, elites in the states of the former Confederacy forced an end to federal occupation and undertook a project to "redeem" their governments, wresting control of Southern statehouses from forces they saw as Northern interlopers, and turning back the reforms imposed upon them during Reconstruction (Foner 1988). The restoration of home rule in the South amounted to a reconstitution of the antebellum political order: the removal of African Americans first from elected office and then from the electorate; and the dismantling of the Republican Party, as an embodiment of Northern interventionism, and of the Populist Party, which channeled the wave of agrarian unrest of the 1870 s and 1880 s into the electoral politics of the 1890s. The resulting one-party political system was anomalous in American history, as was the racial caste system and single-crop tenancy economy that grew along with it (Schwartz 1976).

The peak periods of lynch mob activity roughly coincided with the disenfranchisement campaign that swept the states of the old Confederacy, starting with Mississippi, which altered its constitution to revoke the black franchise in 1890. North Carolina followed suit in 1900, after Republicans had briefly regained, and then quickly lost, control of the statehouse. Though Georgia had enacted some

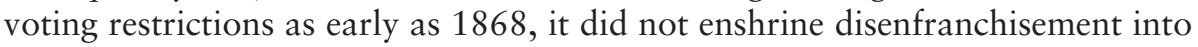
its constitution until 1908. In each case disenfranchisement came with a wave of open fearmongering against African American citizenship. In Mississippi, disenfranchisement was justified as a "legal defensible substitute" for the violence and routine election fraud that had upheld white supremacy in the state (Ayers 1993, 147). In North Carolina, disenfranchisement came after two viciously white-supremacist election campaigns waged by Democrats to first regain control of the state from the Republicans and Populists, and then to lock in their majority with efforts to "congeal their power into state policies and institutional rules" (Redding 2003, 129). The architect of Georgia's disenfranchisement bill, Thomas Hardwick, said it was designed to entrench white control of the state, making sure "that the Negro shall not be left around the corner" waiting to emerge as a force in any future election (Hardwick in Kousser 1974, 221). One of the "great" achievements of the Southern Democratic Party was their capacity to absorb the Populist insurgency, thereby isolating the Republican Party as the only source of opposition to Jim Crow.

It bears noting as well that the analytic distinction between the economic and political systems of the period was less than fully realized on the ground. Beck and Tolnay note that economic competition between blacks and whites was especially both fierce and direct in the South, where the dominance of tenant farming and the crop-lien system mired most farmer-workers in debt peonage (Beck and Tolnay 
1990). The power of landlords in this system, however, depended substantially on support from the state (Schwartz 1976). It was discontent over that system that fueled the Populist revolt of the 1890s, which brought temporary unity among poor black and white rural voters in the South before electoral dissent was obviated by disenfranchisement, and before white elites aligned poor whites against blacks through the propagation of extremist ideology and terror. These brief reflections suggest that in addition to economic factors any account of white-onblack violence in the South must attend to the political context. This can be most succinctly captured by Republican vote share, given uneven Populist penetration and eventual absorption by the Democratic Party.

\section{Averted Lynching}

The idea that our understanding of white-on-black lynching has been limited by selection on a contingent outcome of "successful" mob formation-where mobs formed with the intent to lynch and succeeded-was first strongly argued by Griffin (1993, 1111), who cited data collected by Raper (1933) showing 648 completed lynching events versus 688 averted lynching events between 1915 and 1933 nationwide. Griffin also noted that the Tuskegee Institute (Ames 1942, 11) reported 762 completed lynching events versus 1,476 averted lynching events for a more extended period, up to 1942. The basic insight is simple: if the object of study is the set of conditions that motivate and/or enable mob violence against blacks, analysis of only completed lynching risks selecting on the dependent variable. Minimally, since the overwhelming majority of mob formation cases proceed to lynching contingent upon the intervention, non-intervention, or unsuccessful intervention of law enforcement, one wishes to understand the social, economic, and political contexts in which law enforcement agents were willing or able to successfully intervene. Relying exclusively on completed lynching inventories produces studies not of the genesis of lynch mobs, but of the conditions under which lynch mobs succeed.

We use as our starting point the definition of lynching established by the NAACP, also used by Beck and Tolnay in the construction of their inventory of completed lynching. This definition requires, for an event to be a lynching, that (1) there must be evidence that a person was killed; (2) the person must have met death illegally; (3) a group of three or more persons must have participated in the killing; and (4) the group must have acted under the pretext of service to justice or tradition. Consequently, we define an averted lynching as an event in which (1) a mob of three or more individuals formed-or was perceived as imminently likely to form; (2) for the express purpose of illegally killing a person under the pretext of service to justice or tradition; and (3) a clearly legible intervention was made with the intent of foreclosing the possibility of mob violence.

Two of the three conditions of our averted lynching definition flow self-evidently from the NAACP definition. Our condition on the legibility of intervention calls for some explanation. This condition is intended to mitigate against the subjectivity of the late nineteenth- and early twentieth-century press accounts from which we draw 
our data. Our search, described in more detail in appendix A, also returned a large set of articles in which reporters suggested that a lynching was "threatened," or that a lynching was "sure to result" or "was for a time quite possible." However, in these cases there is no report of a mob actually forming, nor was the risk of lynching assessed by contemporary actors as high enough to undertake any actions that would leave a more distinct trail of evidence that a lynching had, in fact, been imminent. These cases are not considered instances of averted lynching. In contrast, the removal of a prisoner from one jail to another, the mobilization of a militia unit, the convening of a special session of court, or the plea of a father to lash instead of lynch his son-to mention a few of the most frequent interventions-leave less room for subjective judgment. These interventions were costly: they either mobilized resources or publicly identified a citizen by name as having opposed the mob. In other words, these were consequential signals of serious attempts to stop lynch mobs. All these interventions are captured in our inventory. Not all of them were successful. Only the successful interventions result in averted lynching events. Our inventory is thus broader than the cases used in this article in a few ways. First, we consider here only white-on-black violence; our inventory also contains different racial configurations of averted and completed lynching events. Second, we consider here only instances in which a mob (as defined previously) actually formed (as versus was perceived as likely to form).

\section{Methodology for Constructing Our Inventory}

Our intent was to create an inventory as complete as possible and representative with respect to the spatial and temporal patterning of lynch mob formation within our three Southern states. We used digitized contemporary newspaper accounts to compile both lynching and averted lynching event data, which we believe to be a sufficiently comprehensive record of these events. We propose a strategy for their collection ${ }^{2}$ and show that the same strategy recovers lynching data that compares favorably with existing inventories of lynching.

Our sample of states includes Georgia, Mississippi, and North Carolina in the time period between 1882 and 1930, since these years are generally accepted within the existing literature as the boundaries of the lynching epidemic. There are exceptions to this practice. Green, Glaser, and Rich (1998) notably extended the analysis through 1938 in their successful challenge of Hepworth and West's (1988) findings that lynching frequency was related to economic performance. But the bulk of the literature, as well as the data on completed lynching events to which we compare the data we collected on lynching and averted lynching cases, cover the period 1882 to 1930 . The convention of using this temporal bounding may or may not have outlived its usefulness. In future work we expand our temporal scope, in part to test the durability of effect for our political variables over a longer period of time. As for our geographic frame, Georgia and Mississippi were chosen because they experienced the largest absolute numbers of lynching events and account for 56 percent of all black lynching victims: 944 deaths (Tolnay and Beck 1995a, 273). North Carolina is included both because it experienced the fewest lynching events of any Southern state and because it serves as 
a representative of the "border South," which had been less dependent on and less committed to slavery than the cotton-producing states of the Deep South.

We collected newspaper articles on both averted and completed lynching events drawn from a systematic, iterative search of digitized archives of major metropolitan newspapers as well as smaller, local press outlets. Metropolitan newspapers were found in the ProQuest Historical Newspapers database, the definitive digital archive of major American newspapers from the 18th to early 20th centuries. This search returned articles primarily from the Atlanta Constitution, New York Times, Washington Post, Baltimore Sun, and Chicago Daily Tribune, among a handful of others. For the local press, we turned to the World Newspaper Archive, a joint project of the Center for Research Libraries and the Readex Division of NewsBank. This search returned articles primarily from the New Orleans Times-Picayune, Macon Telegraph, Augusta Chronicle, Charlotte Daily Observer, Dallas Morning News, and Kansas City Star, along with a small set of others. The resulting collection of coverage reveals the intensity and national scope of the attention paid to lynching in the news media of the time.

The articles we certified as fitting our definition of averted or completed lynching are all event narratives, in which a person (or persons) was (were) accused of a crime or violation of racial norms, and were either pursued or threatened by a mob, which either succeeded or was frustrated in its attempt to lynch. From these accounts we have systematic information on place (at the settlement level) and time (to the nearest day), on the race and usually gender of the victim(s), the justification given for the mob's action in the form of an accusation of criminality or racial transgression against the mob target, and the racial makeup of the mob. In the case of completed lynching, the method of execution employed by the mob was also reported in most narratives. More rarely, details included indications of whether the violence was excessively brutal or ritualistic, or whether members of the mob were masked. All of these details, where available, were recorded for every event, along with the names of mob targets and public officials, governors, sheriffs, and judges or other citizens involved, resulting in an inventory of lynching and averted lynching with more detail than was previously available. In this article, we concentrate on the dynamics driving the spatiotemporal unfolding of lynch mob formation and will not fully exploit the richness of this data structure.

In relying on data collected from newspaper accounts we encounter two distinct problems: factual accuracy and coverage bias. By factual accuracy, we mean whether or not the information reported in these articles faithfully recounts actual events. By coverage bias, we mean whether our data are biased by patterns of news production. An absence of reporting on mob formation could indicate a lack of news coverage in general from that area, or a de-emphasis on the matter vis-à-vis other news. ${ }^{3}$

The existing literature concludes that the "hard news" aspects of media accounts are generally accurate, though the decision to cover or not cover a specific event is subject to a range of biases, from geography to ideology (Franzosi 1987; Earl et al. 2004; Myers and Caniglia 2004; Ortiz et al. 2005). Given that 
we are not only interested in the geographic location of these events, but also in their temporal patterning, coverage bias can also occur in distinct time windows for the reasons previously suggested.

To test for the robustness of factual accuracy and presence of coverage bias in our data set compiled from only digitized media through our search strategy, we compared our inventory of completed lynching with the Beck-Tolnay inventory, which is fact-checked against newspaper data from digital archives, local papers not digitized, and genealogy searches for lynch victims. We found a high degree of factual accuracy, as well as a high coverage rate for which no systematic spatial or temporal bias was detected. On average our search strategy produces almost 90 percent of the cases in the Beck-Tolnay inventory, which can be seen in a state-level breakdown in table 1. In Georgia and North Carolina, we found 90 percent of the events. In Mississippi, we missed about 15 percent. We claim to have found a match only in cases that occurred within the same state, around the same time (differences in days in our inventory and the Beck-Tolnay inventory is 1.12 on average, $\mathrm{SD}=3.82$ ), centering on victims whose names were identical or nearly identical in the Beck-Tolnay inventory. We also found that the race of the victim(s) and composition of mobs was the same in 98 percent of cases, and crime accusation against lynch victims coincided in 90 percent of cases. Our search strategy finds the overwhelming majority of lynching incidents without relying on the Beck-Tolnay inventory. That is to say, nearly the same inventory can be compiled with modern techniques of data collection thanks to the increasing availability of digitized historical media. From the newspaper searches, we discovered only a handful of lynching events (mostly with unnamed victims) that are not part of the Beck-Tolnay inventory.

The temporal distribution of the number of lynching events is displayed on the four panels of figure 1 comparing our data collection and the Beck-Tolnay inventory. ${ }^{4}$ Based on the above, we conclude that our search strategy accomplished a reconstruction of almost the entire universe of lynching events reported by Beck and Tolnay, without detectable gaps in coverage.

Can this robustness claim be extended to our inventory of averted lynching? It is not possible to give an ultimately affirmative answer. However, close reading of archival press clippings shows that the contemporary press covered lynchings and averted lynchings within the same "genre" of journalism (Platt 1981).

Table 1. Counts of Completed Lynching Events of Black Victims by White Mobs

\begin{tabular}{lccc}
\hline & $\begin{array}{c}\text { Lynching events in the } \\
\text { Beck-Tolnay inventory }\end{array}$ & $\begin{array}{c}\text { Matched lynching events to } \\
\text { the Beck-Tolnay inventory }\end{array}$ & Coverage \\
\hline Georgia & 350 & 315 & $90.00 \%$ \\
\hline Mississippi & 381 & 327 & $85.83 \%$ \\
\hline North Carolina & 63 & 57 & $90.48 \%$ \\
\hline Pooled states & 794 & 699 & $88.04 \%$ \\
\hline
\end{tabular}

Note: Events were recomposed from the victim inventory based on the time and location of victims lynched. 
Figure 1. Temporal distribution of lynching events based on the Beck-Tolnay (B-T) Inventory and our data collection (Hagen-Makovi-Bearman Inventory, H-M-B), 1882-1930

Georgia
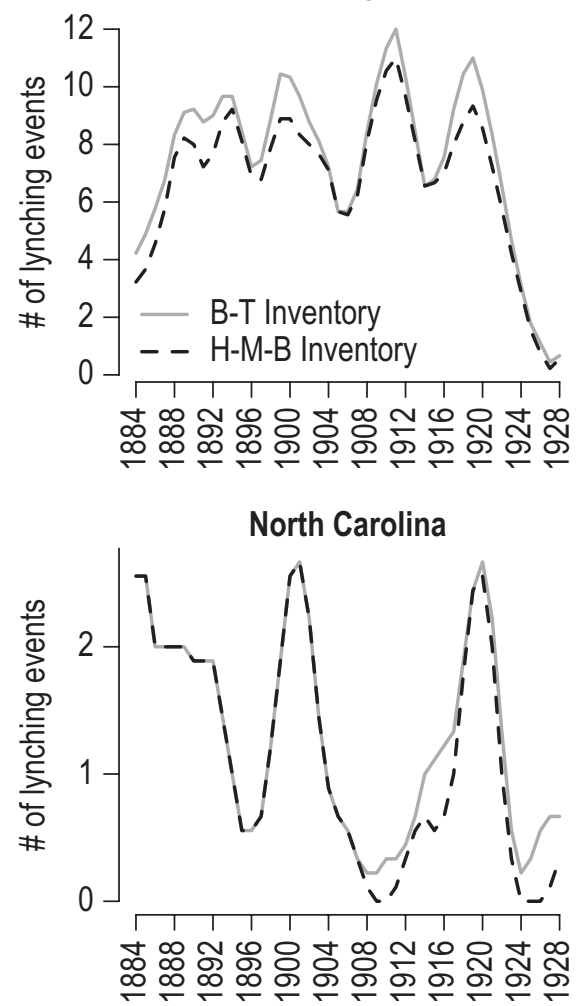

Mississippi

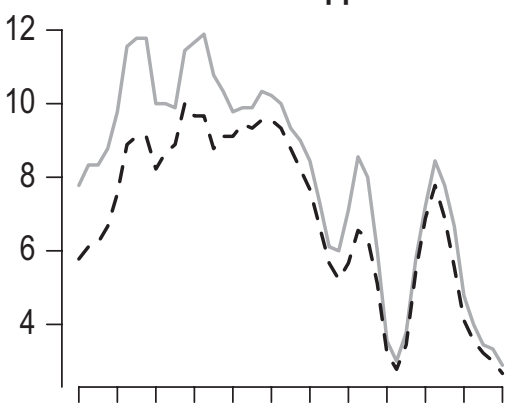

范

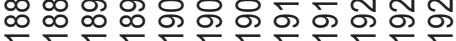

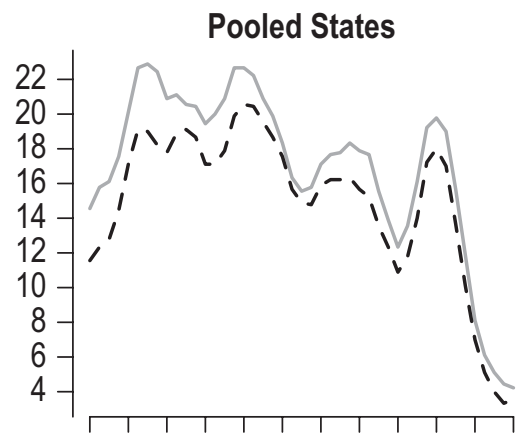

必

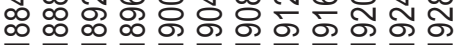

Note: Time series are twice-smoothed three-year moving averages.

Indeed, in several cases, stories of averted lynching become stories about completed lynching over the span of days or weeks, as a mob was repelled and returned later to murder its target. It should also be noted that a subset of completed lynching stories recount interventions that ultimately fail. Completed and averted lynching both trace the same storyline, and the vocabulary linked to lynching and mob violence is common to both. Completed and averted press narratives each begin with the allegation of a specific crime or racial transgression, which triggers retributive events, either legal or extralegal in nature.

In order for press bias to have deformed the archival record here one must believe that journalists were aware in advance which mob formations would succeed and which would fail, and systematically shaped their reporting to privilege one type of event over the other, or selectively repressed averted events despite the newsworthiness of reporting on a crime. This idea lacks face validity. A more serious challenge would be if averted lynching events were associated mostly with less serious crimes or transgressions, and were not reported for that reason. This was not the case: the accusations against mob targets in averted 
and completed cases were statistically speaking the same in Georgia and North Carolina. In Mississippi, successful intervention was more likely when the target of the mob was accused of murder, an event likely to be covered by the press. These relationships are reported in figure 2 .

\section{Data, Variables, and Method}

For this analysis we collected data on factors identified in prior literature as most strongly associated with lynching, most importantly the relative size of black population, dependence on cotton production, and political climate (Beck, Massey, and Tolnay 1989; Beck and Tolnay 1990; Olzak 1990; Tolnay and Beck 1995a, 1995b; Tolnay, Deane, and Beck 1996; Bailey et al. 2008; Gullickson 2010). If selection on the contingent outcome of mob success does not matter, then the expectation is that all of the relationships between these factors and lynching that were previously observed (and none of the relationships previously not observed) should be the same. In contrast, if selection has shaped our understanding of the dynamics of mob formation-if the conditions under which mobs fail are significantly different from those under which mobs succeed-it necessarily follows that some of the previous findings (both positive and negative) will need to be interpreted in this new light.

For all measures we use the county as the basic geographic unit of analysis, allowing us finer resolution than previous studies of state-level dynamics. From prior work, we expect that percentage black population has a curvilinear relationship to lynching. Following Blalock's power threat hypothesis, the larger the share of a population comprised by blacks, the more frequent lynching events would be, up to a threshold associated with a "critical mass" above which the black population would be politically active (Blalock 1967), triggering alternative means of political oppression by the white establishment (Reed 1972; Creech, Corzine, and Huff-Corzine 1989; de la Roche 1996). Cotton dependency is also expected to relate positively to lynching, as has been shown with a variety of empirical strategies in different geographic contexts. Given the centrality of race and cotton to Southern society in this period, we expect that these associations will also be important drivers of mob formation, whether or not the mob is successful. Change in cotton production has also been established as inversely related to lynching. A similar association is expected for averted lynching events.

The political climate has been linked to lynching indirectly: using the relative size of the black population to infer the salience of political (and economic) struggle between racial groups, and directly through Democratic vote share and disfranchisement. As previously mentioned, the influence of political variables on lynching is an area of contention. In theory, lynching should decrease after disfranchisement, as a costly and unnecessary form of repression (Phillips 1987). However, this does not hold in the American South (Beck, Massey, and Tolnay 1989). We argue that an association between Democratic control, Republican oppositional strength, and lynching is likely to express itself with respect to intervention. Specifically, we expect that successful lynching events are more likely where the political discourse generated a more favorable climate for racial 
Figure 2. The distribution of crime accusations against lynch mob targets in cases of completed lynching events and averted lynching events, 1882-1930
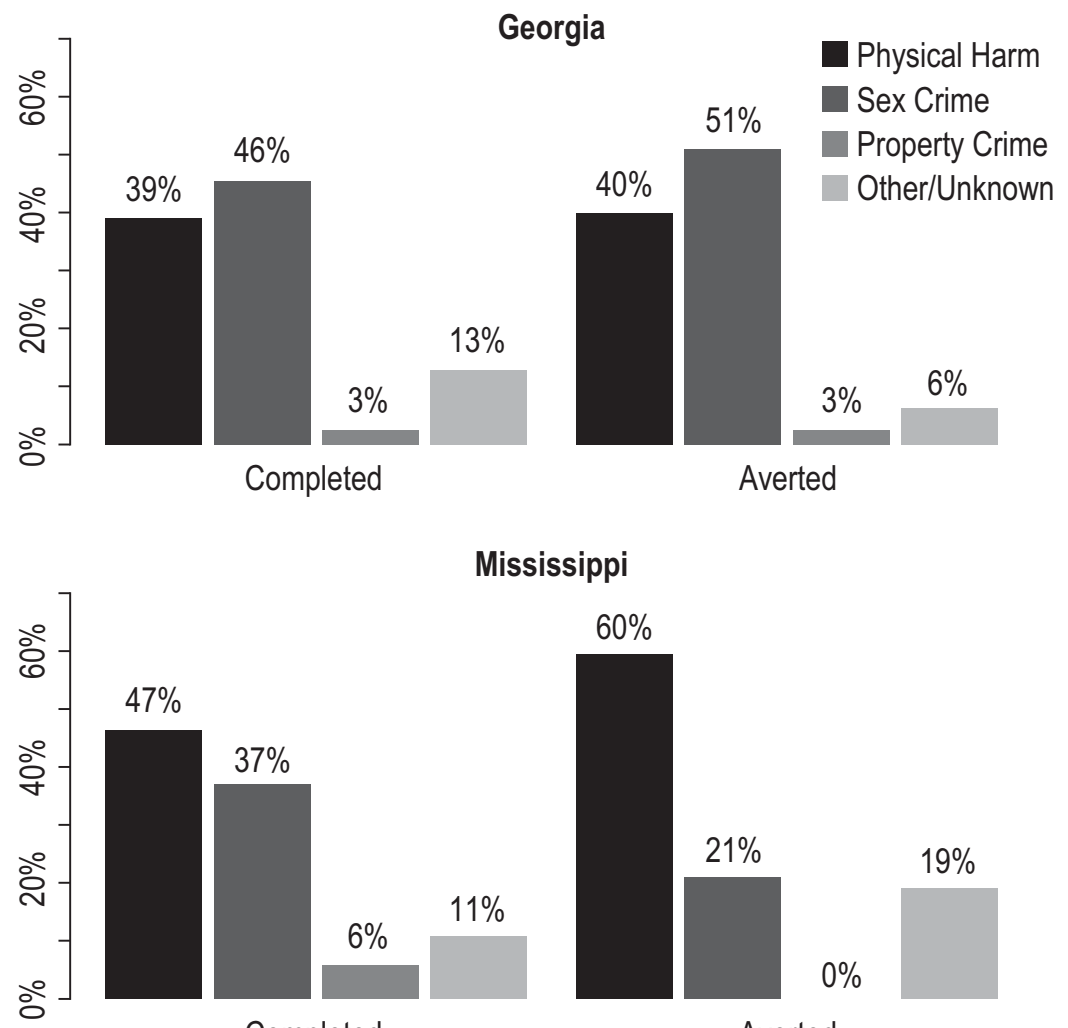

Completed Averted

North Carolina

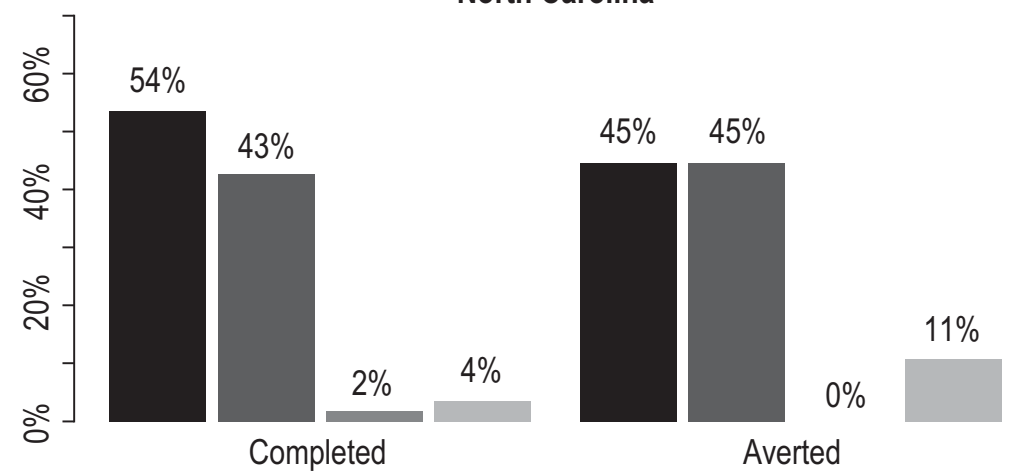

Note: Components of accusation categories are as follows. Physical harm: murder, attempted murder, physical assault, physical threats, and accessory. Sex crime: rape and attempted rape, being "found in a woman's room," inappropriate communications with a woman, miscegenation. Property crime: burglary and robbery. Other: arson, political activity, racial caste transgressions, "being of bad character," and mistaken identity. 
violence while suppressing the likelihood of law enforcement intervention. Based on this logic, the larger the counterforce against the Democratic Party, the more likely lynching events will be averted-and consequently, the less likely that mobs will be able to murder their intended targets.

Prior events can also influence the likelihood of collective violence. Tolnay, Deane, and Beck (1996) and Stovel (2001) found that memory of prior lynching events is durable. Previous mob formation events in a county can, for years, either increase or decrease the risk of subsequent lynch mob activity, because these events provide a model for "mob success" or for successful intervention. Finally, population density - a proxy for the development of transportation and communication grids, and agriculture dependence-is likely to be related to both mob formation and intervention, facilitating or hindering these phenomena.

\section{Data}

We drew population data from the decennial censuses, and applied linear interpolation between census years. Cotton production data came from two different sources. The first is the Agricultural Census, ${ }^{5}$ which gives accurate data at the county level the year before censuses. To enhance the quality of the data in inter-census years, we relied on estimates published by the National Agricultural Statistics Service that give yearly measures at the state level for the entire time period we analyze. It also provides these data at the county level in North Carolina after 1925, and in Georgia and Mississippi after 1928. ${ }^{6}$ We distributed the state-level data based on the cotton-production structure within states, derived from census years, and applied linear interpolation in between. The political climate was described through county-level vote totals for presidential elections. ${ }^{7}$ Data on returns for these elections are consistently available at the county level. Any missing data are filled in by linear interpolation. We matched candidates to their political parties and coded vote totals as falling into one of four categories: Democrat, Republican, Populist, and Other.

In this article we intend to account for both the spatial and temporal patterning of completed lynching and averted lynching events, and understand how they interact. We believe that any theoretical argument that aspires to establish causality must account for both the temporal and spatial patterning of lynching. This is not to say that focusing on temporal patterning exclusively cannot be fruitful-to the contrary-but the causal interpretation of results from such an analysis needs to make the sometimes tacit assumption that lynching events are the same regardless of local context, and that the characteristics of the lynching epidemic are stable across changing geographic scales and locations. That said, there are some powerful constant effects that can be consistently observed when data are aggregated over space. Here, for example, Beck and Tolnay's core findings - that lynching is more frequent when economic pressures are present, either because of inflation or because of decreasing cotton prices, after controlling for the amount of cotton produced-built on data from the Deep/Cotton South (Beck and Tolnay 1990; Tolnay and Beck 1995a) are supported even when restricting the geographic frame to our three states. 
On the other hand, lynching events occur in local communities, often undertaken by community members against victims known to them. The killings are public in most cases, widely discussed, and reported in the press, often up to a national audience. These events become part of the local history of race relations and define community identity both internally and in relation to larger cultural and political units. Approximating these communities in a more granular way, rather than simply aggregating lynching counts for the Deep South as a whole, has already been attempted by Tolnay, Deane, and Beck (1996) and Stovel (2001). Although the research designs and methodologies are very different in these inquiries, they both attempt to better understand the temporal and spatial patterning of lynching by looking more closely at their local history.

There is wide agreement that the meaningful unit of analysis in the South at this time is the county. However, county boundaries in this period in the South were deeply unsettled. Over the course of our period, counties annex the territory of neighboring counties; new counties are born, stitched together from pieces of several existing counties. Stovel does not address the problems that arise from these changes. In contrast, Tolnay, Deane, and Beck engage with the changing areal unit problem, by restricting analysis to short periods around census years (1996) and clustering counties in which boundary changes occurred. These strategies work well because measurement of key variables is more accurate (by restricting observation to moments around census years, interpolation is avoided) and because country boundary changes are minimized. County clusters were also used by others in historical work (Land, Deane, and Blau 1991; Hargis 1994; Baller et al. 2001; Messner, Baller, and Zevenbergen 2005).

The major drawback of this approach is that the county clusters produce areal objects that are meaningless socio-political entities, since in this period the organization of law enforcement is always at the county level. Across long historical windows, county clusters become increasingly heterogeneous and describing them with aggregate values and means becomes necessarily less informative. ${ }^{8}$

In this article we locate lynching events (completed and averted) to the nearest settlement and locate settlements in counties in order to build a county-level lynching history for counties present in 1880. We fix these units for the entire time period, and given that we have settlement-level data for most completed and averted lynching cases, we can attribute events within the boundaries of 1880 counties. $^{9}$ The 1880 county boundaries come from the National Historical Geographic Information System, ${ }^{10}$ and using an appropriate projection, we overlaid the event data on these county maps. In cases where data was not available at the settlement level ( 8 percent and 8 percent for completed and averted events, respectively), we assigned them to the county-centroid based on the centroids that match the event's year. ${ }^{11}$

Taking 1880 counties as units of analysis is a compromise between meaningful units of analysis and feasibility. On the negative side, we lose observation on some meaningful law enforcement units over time. On the positive side, this strategy protects us from confounding change in population and production, and 
most importantly change in lynching counts, with change in territory. Further, these units are still more homogeneous than the larger county clusters. Finally, in 1880, these counties were organized as administrative units that defined the boundaries for law enforcement and court circuits, and shaped transportation, trade, and communication networks in the region. Working with 1880 county boundaries allows us to carry the 1880 units forward for the entire time period, which means that the history of lynching in these three states can be understood for a longer interval than allowed for in the Tolnay-Deane-Beck (1996) approach, and at a much finer level of temporal aggregation as compared to the Beck-Tolnay time-series approach.

\section{Variables}

We measure the ratio of the black population to the total population on a $0-100$ scale. Cotton dependency is measured as the ratio of acres of cotton to acres of farmland on a $0-100$ scale. Change in cotton production is measured as the difference of production in 1,000 bales from the previous year. Republican share is measured as the ratio of votes cast for the Republican Party presidential nominee to total votes cast in the most recent presidential election on a 0-100 scale. Low and high Republican share are dummy variables, where "low" stands for the lowest 25 percent of counties in the state for a presidential cycle and "high" is the highest 25 percent. These variables remain constant for a four-year period starting in September of the election year. Events that occurred previously in the county are captured by a count and a simple decay effect that models the process by which memory of the event fades over time. Population density is the ratio of the total population per square mile divided by 100 .

The spatial and temporal distribution of our dependent variables-completed lynching events, mob formation events, and averted lynching events-are contrasted and reported in table 2 and figures 3 and 4. Aggregating over space and time (to the state level), there were significant differences in lynch mob success. From table 2, we can observe that in Mississippi, 85 percent of all mobs succeeded in killing; in Georgia, 59 percent were successful; and in North Carolina, 50 percent succeeded.

Aggregating over space within each state we observe the temporal pattern, as reported in figure 3. In all three states, completed and averted lynching events follow a similar pattern, very strongly in Georgia and North Carolina, while slightly less so in Mississippi. Finally, figure 4 reports the county counts of averted and completed lynching events for each state for the entire period, showing the strong differences in the geographic patterning of mob lethality.

\section{Method}

The strategy outlined above shows the skeleton of the data structure we built and brings out the key assumptions necessary to build such a data structure. We implemented a Cox proportional hazard model (Cox 1972), in which the units put at risk of experiencing events of lynching, lynch mob formation, and 
Table 2. Count of Completed and Averted Lynching Events of Black Victims by White Mobs Based on the H-M-B Inventory

\begin{tabular}{lcccc}
\hline & $\begin{array}{c}\text { Matched lynching } \\
\text { events to the } \\
\text { Beck-Tolnay } \\
\text { inventory }\end{array}$ & $\begin{array}{c}\text { Mob formation } \\
\text { events that } \\
\text { resulted in at } \\
\text { least one victim }\end{array}$ & $\begin{array}{c}\text { Mob formation } \\
\text { events that were } \\
\text { successfully } \\
\text { averted }\end{array}$ & Mob success \\
\hline Georgia & 315 & 310 & 218 & $59 \%$ \\
\hline Mississippi & 327 & 330 & 57 & $85 \%$ \\
\hline North Carolina & 57 & 55 & 56 & $50 \%$ \\
\hline Pooled states & 699 & 695 & 331 & $68 \%$ \\
\hline
\end{tabular}

Note: Counts of "matched lynching events" and those of "mob formation events that resulted in at least one victim" differ slightly. Differences arise from the fact that in a very small share of cases, we did not match the racial configuration of events reported in the Beck-Tolnay inventory. We use the data we collected in the remainder of the paper, given that averted lynching data were collected with the same strategy, and from the same sources, therefore, we assume that the error structure of these data for averted lynching events and completed lynching events is not different.

Figure 3. Temporal distribution of lynching events, averted lynching events, and events of mob formation, 1882-1930, based on the H-M-B inventory

\section{Georgia}

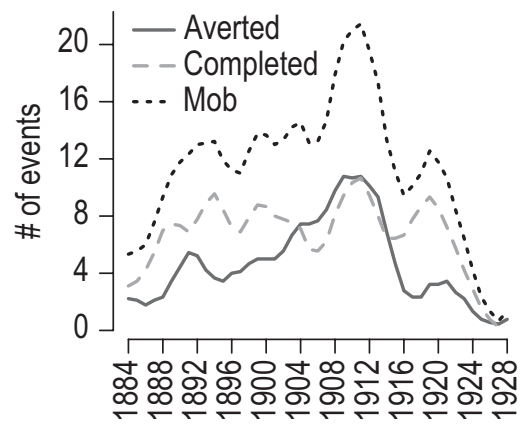

North Carolina

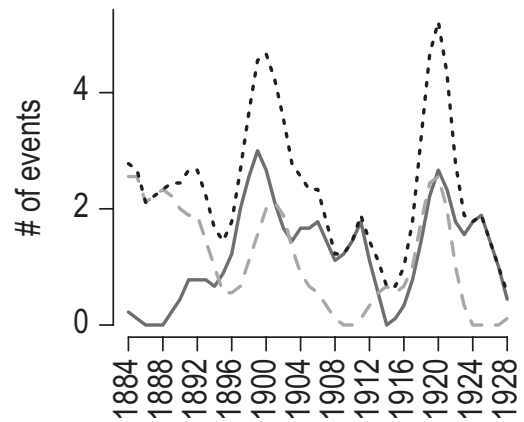

Mississippi

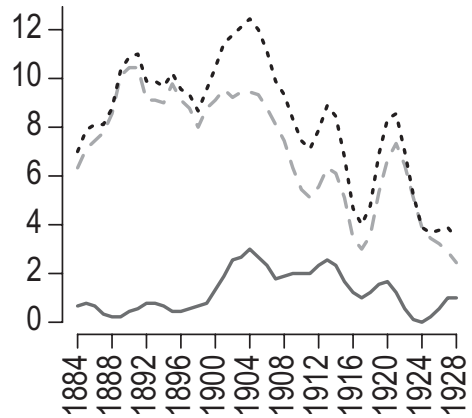

Pooled States

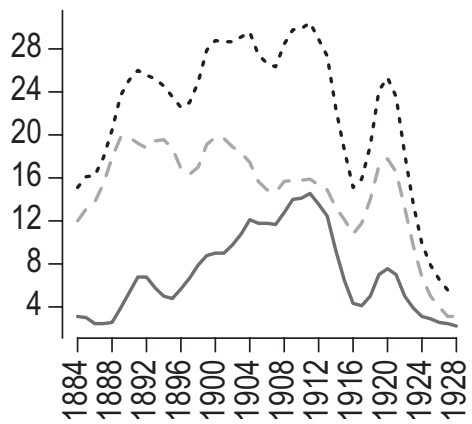

Note: Time series are twice-smoothed three-year moving averages. 
Figure 4. Spatial distribution of lynching and averted lynching events, 1882-1930, based on the H-M-B inventory
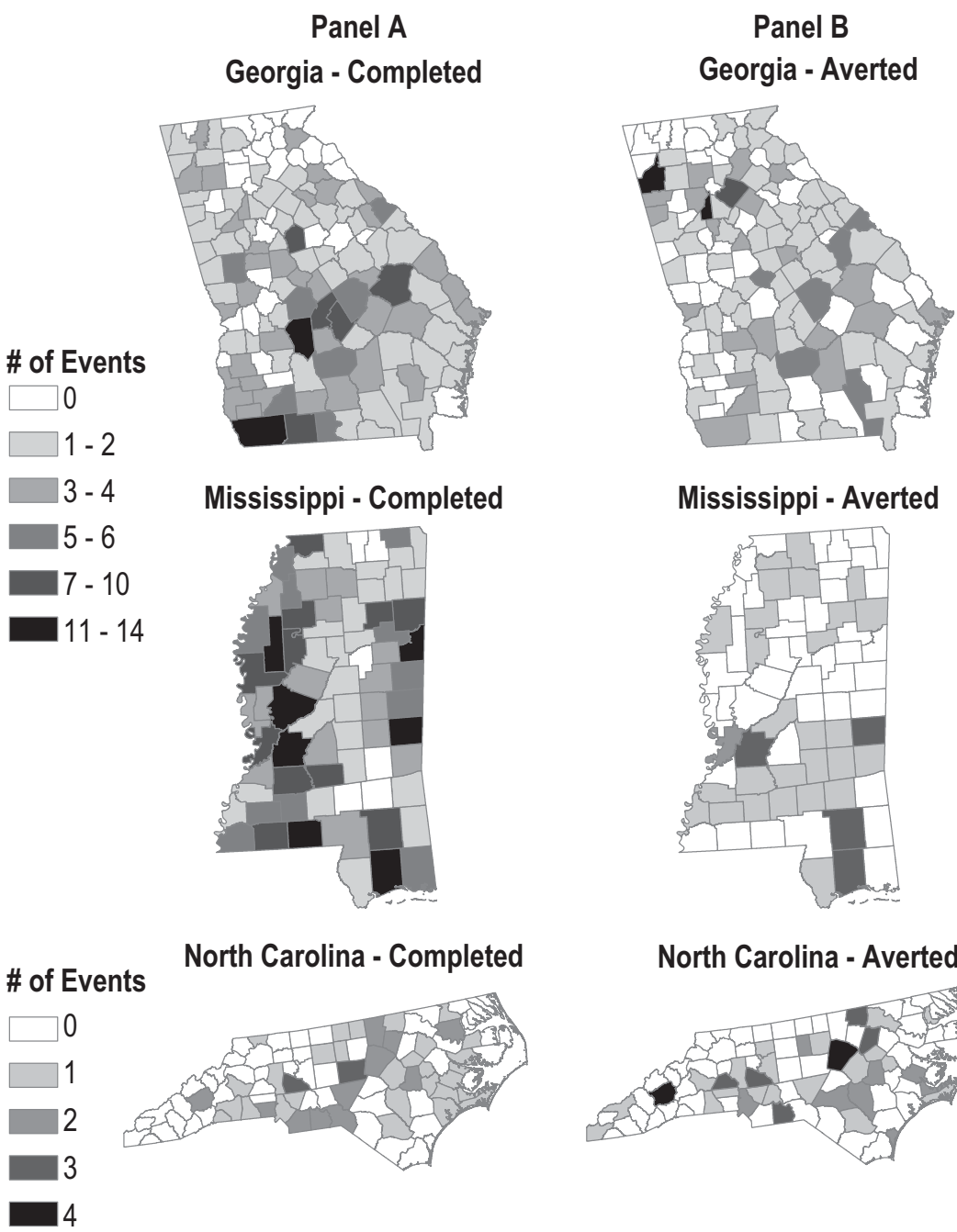

North Carolina - Averted

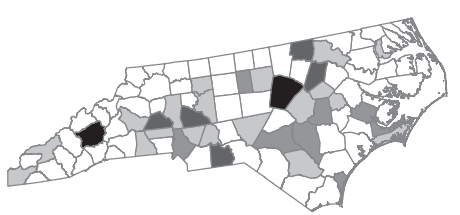

Note: Note the scale change between North Carolina and Mississippi-Georgia.

successful intervention against lynch mobs are 1880 counties allowing for multiple failures over time. More formally, we estimated the following model:

$$
h\left(t \mid \mathbf{x}_{\mathbf{j}}\right)=h_{0} e^{-\mathbf{x}_{\mathbf{j}} \boldsymbol{\beta}_{\mathrm{x}}}
$$

where $h\left(t \mid \mathbf{x}_{\mathbf{j}}\right)$ is the hazard rate of the $j$ th subject, and the argument $\mathbf{x}_{\mathrm{j}}$ refers to the individual-level descriptors and can be both time varying and time invariant. $h_{0}$ 
is the baseline hazard, which is given no particular parameterization and is left unestimated. Finally, $\beta_{\mathrm{x}}$ is the vector of regression coefficients that is estimated from the data. All counties are censored in 1930. Our temporal resolution is seasonal (spring, summer, fall, winter), constructed around cotton production. ${ }^{12}$

We specified memory to leave a trace as long as six years (Tolnay, Deane, and Beck 1996; Stovel 2001). Given that there is no empirically grounded theory that would help us model memory decay in general, and memory of lynching in particular, we followed a strategy similar to Stovel's in which the half-life of memory of an event is one year. We further assumed that memory was additive: if more than one event happened in a six-year period, the remaining memory of the old event and the memory of the new event simply aggregate. The findings we report are robust to a wide range of memory specifications. ${ }^{13}$

\section{Findings}

Using our modeling strategy, we first succeeded in replicating the key findings of the literature on completed lynching events: in this model, our dependent variable is time to the next lynching event. Results are presented in the first panel of figure 5.

Prior events in a county are, as anticipated, positively associated with the likelihood of a completed lynching. Proportion black shows the expected curvilinear relationship with completed lynching events. ${ }^{14}$ The local maximum of the inverse U-shaped curve is at 62.8 percent-this is where lynching peaks. We also observe support for the core role that economic composition plays in driving lynching. A 1-percent increase in cotton dependency results in a 1.47-percent increase in the hazard of lynching. Change in cotton production, however, does not have a statistically significant relationship with lynching. Political factors matter. High Republican vote share decreases the hazard of lynching by 67.8 percent. The effect of population density is curvilinear, as expected, but while substantively significant, it is not statistically significant at the 5-percent level.

Model results with respect to mob formation with the intent to lynchcombining successful and averted lynching into what we believe is a more meaningful dependent variable that avoids selection on a contingent outcome-are reported in the second panel of figure 5. Here, the dependent variable is time to next mob formation event. Results are similar to those for successful events; most notably, economic pressures elevate the risk of mob formation. The peak in percent black population occurs slightly earlier, at 58.9 percent. The effect of high Republican vote share substantially weakens with 22.5 percentage points, but remains significant and decreases the risk of mob formation events. The general continuity of results is not surprising, since two-thirds of the events are instances of mob formation where the mob successfully kills.

To address the question of whether and how averted lynching differs from completed lynching, we analyzed averted lynching events separately: see the third panel of figure 5. The factors that seem to drive mob formation exhibit similar associations. However, the effect of Republican share changes direction: while high Republican vote share decreases the likelihood of lynch mob formation, 
Figure 5. Results from Cox proportional hazard models for completed lynching events, mob formation events, and averted lynching events
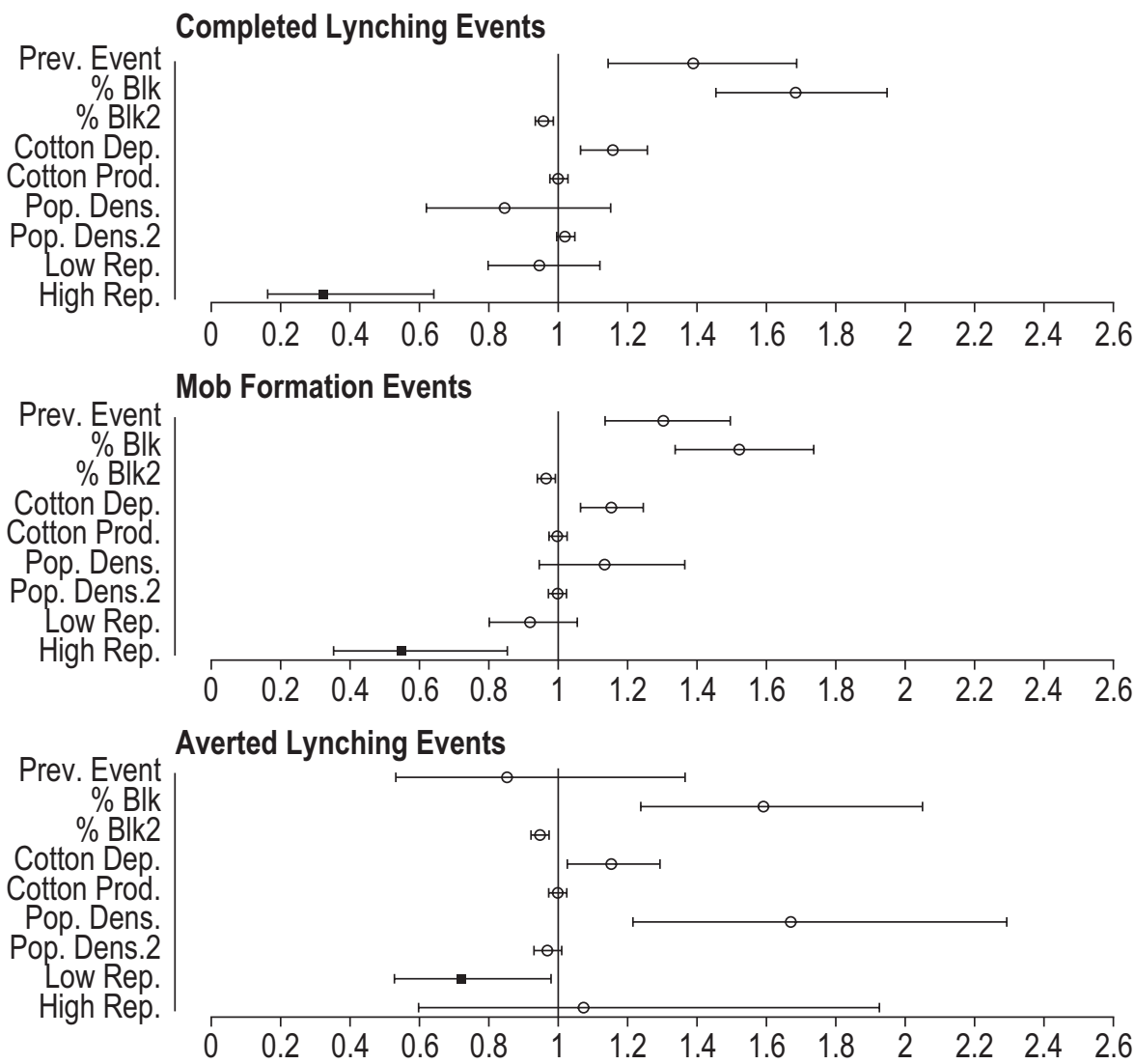

low Republican share decreases the chance of averted lynching by 28.1 percent. When Republican share is low, mob formation events that end with law enforcement intervention become increasingly unlikely. This association between successful interventions and political climate has not been seen before, due to lack of data on averted lynching.

This makes possible a new interpretation of the association between low Republican share and successful lynching; namely, that political climate mediated the efforts that were made to save potential lynch victims from mobs. The striking difference in terms of the directionality of the effect suggests that certain contexts made intervention more or less likely and more or less successful, and therefore shaped the pattern of lynching in the American South.

Our modeling strategy rests on a few assumptions: first, that censoring is non-informative, meaning that there is no selection into being censored or lost for follow-up. This is easily met, since all counties are censored at the same time. Second, that hazard functions are proportional over time. Grambsch and Therneau perfected a test to address this question, which is based on Schoenfeld 
residuals and directly investigates if the log hazard-ratio function is constant over time (1994). All of our models passed the global test. We also ran the link test to check for omitted-variable bias (Cleves et al. 2002 [2010], 205). There is no evidence that our models are incorrectly specified.

\section{Discussion}

The construction and analysis of an inventory of averted lynching makes several contributions: first, it begins to realize the promise of a long-standing line of speculation, demonstrating the possibility of compiling such an inventory through digitized newspaper archives. Second, we have shown that lynch mob formation, rather than lynch mob success, is the most appropriate dependent variable for understanding the drivers of lynching. Third, we show that lynch mob lethality strongly depends on the willingness or ability of the state to intervene on behalf of potential victims. Variability in the frequency and success of such interventions in this period, in the three states under study, is significantly influenced by the political climate, operationalized here through the county-level share of votes for Republican candidates in presidential elections. We find that the effect of party vote share on increasing or decreasing the risk of lynching is at least as large as the effect of cotton dependency, the key variable upon which most economic competition theories of lynching are based. This resonates with findings from a line of research stretching back more than forty years to Snyder and Tilly (1972), concluding that collective violence is always, at root, a matter of power and politics.

Prior work turned to economic explanations after the failure to uncover convincing evidence that lynching was driven by political competition between Southern whites and blacks. Our findings suggest that lynching was more frequent precisely in times and places where political competition was curtailed by the establishment of the one-party South. White-on-black violence was openly political in the Reconstruction era-Foner writes of a climate of white mob attacks on Republican newspapers, elected officials, and black voters, including episodes of mass violence like the Colfax massacre of 1873, none of which were clothed in the judicial rhetoric that characterized lynching in the Redemption era and beyond. After the collapse of Reconstruction blacks were increasingly marginalized, purged not only from elected office and the electorate but from positions in law enforcement and the judicial system in general-blacks briefly served on Southern juries in the Reconstruction era, but were effectively barred from such service afterward (Foner 1988, 595). As late as the 1930s, well into lynching's decline, contemporary observers noted that "the Negro's political impotence was pointed to as a factor in the indifference of officers toward the prosecution of mobs" (New York Times, 10 November 1931). Lynching was often justified as a remedy for the unwillingness or inability of the judicial system to punish black transgressors to the satisfaction of the mob. This argument apparently resonated with the sheriff who saved Jim Walker from an Atlanta mob by promising-even before Walker was in custody, let alone tried in court—-to have him legally hanged. It would seem that in localities where Democratic electoral hegemony was most complete during 
the establishment of the southern racial caste system, law enforcement officials were less likely to make even this modest gesture toward the citizenship rights of African Americans. Not surprisingly, Ware's lynching came during a period of Democratic electoral dominance in that county.

That noted, the idea motivating this article is that by selecting on the outcome variable in the study of lynching, we lose insight into basic dynamics. This turns out to be true-while economic factors play a role in inducing mobs to strive to lynch blacks, political factors turn out to be equally, if not more, dispositive as a mechanism shaping mob formation and success. With respect to creating the opportunity for successful intervention leading to an averted lynching, political factors appear to be central. In counties where sheriffs operated in a climate of Democratic hegemony, the option of stepping into halt a lynching-even if only for a brief moment until it could be "legally arranged"-was of little significance.

Here, we have focused on lynching events directly averted through intervention. Our inventory also makes possible the study of proactive intervention, occasions on which sheriffs and other actors whisked suspects away, well before a mob formed, simply on the threat of lynching. The analysis of the unfolding contexts in which such steps were taken is, however, beyond the scope of this article, which concentrated first on establishing that an inventory could be constructed, showing that the search strategy identifies both completed and averted lynching events, and demonstrating that both events, when analyzed together and separately, provide evidence for critical political processes, thereby returning our understanding of the lynching-era South to that host of grim settings in which men kill other men simply because they are able.

\section{Notes}

1. At the risk of being didactic, ever since lynching studies have been a part of the sociological problem set, we have assumed that social and economic changes generate states of mind (frustration, fear) that express themselves in mob formation that results in lynching. But we have been inferring these drivers from a subset of mob formation cases that successfully killed. The same problem long haunted studies of collective action, where intensity of sentiment was imputed from observed protest group size, without considering how threshold effects and other dynamics could influence the size of groups, independent of the intensity of their engagement (Granovetter 1978).

2. At the 2010 annual meeting of the ASA, E. M. Beck described an ongoing datacollection project in a talk titled "Averted, Foiled, and Threatened Lynchings in the South," reporting preliminary results from an effort to identify victims of averted or threatened mob action using searches on Ancestry.com, NewspaperArchive. com, and Geneology.com. Seymour Spilerman also reports having collected data on averted lynchings covering a narrower window for some Southern states using manual newspaper searches. Our strategy to find averted lynching events differs, as described in appendix A. However, given that no scholarly work on these datacollection efforts has been published, we are unable to contrast our inventory to them, or others.

3. In the vast majority of cases, the newspaper article reporting that a mob formed with the intent to lynch also provided the first report that the crime or transgression had 
been committed. Only in the few cases where no suspect was immediately identified (giving potential lynch mobs no specific target) was the crime reported outside the context of potential or eventual lynching, followed by a subsequent report of a lynch mob. The reporting of crimes and transgressions seems to have been the focus, with lynching as a routine and expected form of retribution.

4. We also replicated the basic time-series analysis conducted by Beck and Tolnay, restricting the geographic frame to Georgia and Mississippi-states belonging to the Deep South or Cotton South-and compared results from the two inventories (not shown here but obtainable from the authors). Effect sizes were not statistically significantly different, and confidence intervals were comparably wide. We also ran simulations to test if there was any temporal variation in matching success. We excluded 10 percent of cases from the Beck-Tolnay inventory at random in Georgia and North Carolina, and 15 percent in Mississippi. We repeated this process a hundred times, and reconstructed the time series, which gave confidence intervals. In all three states, the number of cases we matched was never below the number we would expect if missing cases were generated by a random process.

5. Inter-University Consortium for Political and Social Research. Historical, Demographic, Economic, and Social Data: The United States, 1790-1970. ICPSR00003-v1. Ann Arbor, MI: Inter-University Consortium for Political and Social Research. http:// www.icpsr.umich.edu/icpsrweb/ICPSR/studies/3.

6. http://www.nass.usda.gov/index.asp.

7. Inter-University Consortium for Political and Social Research. United States Historical Election Returns, 1824-1968 [Computer File]. ICPSR00001-v3. Ann Arbor, MI: Inter-University Consortium for Political and Social Research [distributor], 1999-04-26. Data on presidential elections were used, given that Mississippi only sporadically reported congressional elections returns at the county level in the period between 1888 and 1906.

8. These issues have been the subject of recent attention, and some other solutions have also surfaced. Gutmann et al. (2012) use a sophisticated strategy based on estimation of standard errors of a generalized Cox regression. This technique is quite elegant but works best with data that come in a cruder temporal resolution than lynching data, which are accurate to the day.

9. See appendix B for the elaborate description of the method we used to construct settlement-level event data, and for further explanation of the modifiable areal unit problem and how it is handled in our work. See also appendix C for robustness checks, where we replicate the analysis using county clusters and more traditional modeling approaches.

10. Minnesota Population Center. National Historical Geographic Information System: Version 2.0. Minneapolis: University of Minnesota, 2011. http://nhgis.org.

11. Three averted lynching events were entirely excluded from the analysis, and descriptive tables as well, as they had no county, just state-level information.

12. We replicated this analysis, changing the length of "ticks of the clock" to one month and to six months. The substantive results of these analyses remain the same. They are available from the authors upon request. Generally, one would prefer finer temporal specification (monthly, over seasons), but this requires more imputation of values. If multiple events happen within an interval, they cannot be disentangled, nor taken into account as multiple events, or multiple failures in the language of event history analysis. While this is exceptionally rare in our data, it does happen. Tied failures are treated using Stata11.2 stcox's "breslow" option clustering standard errors on county identifiers, and stratifying for the failure risk group for each time 
span (Prentice, Williams, and Peterson 1981), which is an appropriate method for treating multiple failure-per-subject data. Using different methods for handling tied failures yields substantively the same results.

13. Other specifications not presented (available on request) differ neither statistically nor substantively, though differences were found in terms of effect size and uncertainty.

14. For legibility, we used a transformed variable by dividing percent black by 10 , and a similar transformation for cotton dependency.

15. Data Source: Center for International Earth Science Information Network (CIESIN)/ Columbia University, International Food Policy Research Institute (IFPRI), the World Bank, and Centro Internacional de Agricultura Tropical (CIAT). 2011. Global RuralUrban Mapping Project, Version 1 (GRUMP, v1): Settlement Points. Palisades, NY: NASA Socioeconomic Data and Applications Center (SEDAC). http://sedac.ciesin. columbia.edu/data/set/grump-v1-settlement-points.

\section{Appendix A. Search Strategy}

As previously mentioned, our search was conducted on digital newspaper databases. To avoid biasing our results, and to catch the broadest pool of news reports, we used the simplest possible search terms: "lynch" and "mob." In each case, a wildcard ( “*”) was appended to the term, ensuring that all variations of the term would be captured. That is to say, articles are returned not only when a mob has attempted to lynch a prisoner, but when a group of lynchers has mobbed a jail, or when a "lynching bee" is averted. Using these broad terms also avoids biasing our results toward or away from any one particular kind of intervention. For example, between 1880 and 1930, in the entire corpus contained in ProQuest Historical Newspapers, the phrase "let the law take its course" occurs almost exclusively in articles related to lynching. But this search string returns only lynching events that are constructed explicitly as circumventing a moribund criminal justice systemindeed, a common refrain in the lynching discourse of the time is that "if only the courts would move more quickly," lynching could be eradicated. That string also biases us toward events in which agents of law enforcement verbally address a mob. Using broader search terms with the wildcard appended also mitigates against problems inherent in optical character recognition (for example, "lynching" may be read by the search engine as "lynchimg," and rejected).

To narrow the results somewhat, our search of the Historical Newspapers database was also restricted by dateline, ensuring that articles were returned only on events that occurred in our three states. Restricting the search to articles datelined in our relevant states (plus the states surrounding Mississippi, to account for the tendency in Mississippi, which has no domestic metropolitan newspaper during our period, for some articles to be filed from neighboring states) reduces the hit number by more than half.

Dateline searches are not possible in the World Newspaper Archive, in part because most small-town papers did not use the dateline system. To combat this, we restricted the search in two ways: first, by searching only local papers published in our states and regional papers in some neighboring states (for example, the Dallas Morning News, in Texas, carried a number of reports of lynchings and averted lynchings in Mississippi). Even with this filter, we were faced with 
a daunting number of hits, since even local papers could carry articles from out of state. It was necessary here to narrow the search by appending certain common words and phrases to our base search terms "lynch" and "mob": for example, "purpose of lynch"" and "elud" mob*" and introducing new search strings that we commonly encountered in the articles recovered in the metropolitan newspapers search: for example, "riddled with bullets," "cooler heads prevailed," and the Boolean string "neck NEAR/2 sav*." We are confident that our thorough reading and coding of the metropolitan press-which in many cases carried pieces that previously appeared in local newspapers-enabled us to compile a large and representative set of vocabulary used to describe lynching and averted lynching events. These words usually relate to specific type of interventions, or mode of execution. This strategy turned up the lion's share of events already found in the metropolitan press, and yielded some new ones. Given that we were searching for twenty different sets of strings and Boolean string permutations, based on what we found through the general search terms in the metropolitan press, we do not believe this narrower search strategy biases our inventory toward or away from any kind of intervention or mode of execution. Furthermore, the overwhelming majority of events that we include also have the general search terms "lynch" and "mob" " in the report, thus those clippings we ended up coding were actually the subset of the ones found by the general strategy. Some exceptions would be instances in which "a crowd of angry citizens" gathered and their target was "spirited away" from the jail to the penitentiary to "avoid violence." We read all the articles returned by the search, and discarded those that did not describe events meeting our definition of either completed or averted lynching.

\section{Appendix B. Defining the Units of Analysis: 1880 Counties}

In this appendix, we describe the modifiable areal unit problem and outline our solution. First, we illustrate through a very simple example how the lynching event history of a county might be compromised due to boundary changes. Our example is of the birth of a county $(\mathrm{C})$ with two "parent counties" that contribute to its formation (A and B). Let us consider the hypothetical scenario that there was a lynching in county $\mathrm{A}$ at $\mathrm{t} 1$, county $\mathrm{C}$ was formed at $\mathrm{t} 2$, and county $\mathrm{C}$ experienced a lynching at $\mathrm{t} 3(\mathrm{t} 1<\mathrm{t} 2<\mathrm{t} 3)$. County $\mathrm{B}$ did not experience a lynching in this time period. Consequently, in the $\mathrm{t} 1-\mathrm{t} 3$ interval, the lynching history is one lynching at $\mathrm{t} 1$ of county $\mathrm{A}$, one lynching at $\mathrm{t} 3$ of county $\mathrm{C}$, and no lynching of county B. This strategy makes a "mistake" in rebuilding county A's and county B's lynching history in the sense that the lynching at $\mathrm{t} 3 \mathrm{had}$ happened on the former territory in either one of them.

In order to avoid such mistakes, we use 1880 counties as units, fix them, and carry them forward from 1882 to 1930 . We demonstrate that attribution of events to settlements and settlements to counties can be done with precision, and we argue that 1880 counties had been meaningful socio-political units and that they approximate communities - that one would analyze in an ideal worldbetter (or at least not worse) than county clusters. 
Fortunately, averted and completed lynching reports follow a common structure. The common elements of this structure include the discovery or the report of a crime or transgression, the pursuit of a suspect, interventions (if any) to stop mob violence, their success or failure, and the account of the lynching if the mob succeeds. All of these happenings are systematically referenced at the settlement level. We collected information for each lynching and averted lynching event on (1) the place where the alleged crime occurred; (2) the place where the lynch mob arose from; (3) the place of the pivotal intervention that stopped the mob; (4) the place where the lynching occurred or where the body was found; and (5) the place named in the dateline, if any (see table B1 for averted lynching events and table B2 for completed lynching events for the relationship of these places).

Ideally, one would wish for data that directly established the place where lynch mobs formed: conceptually, the clearest geography that gets the analyst the closest to tackling questions of collective violence. Unfortunately, among the places we listed above, the site of mob formation is the one that is most difficult to establish directly from the reports. However, the place of the alleged crime and the geography of intervention or lynching is reported with a much higher frequency. It turns out that the place where the mob was reported to have come from generally coincides with these other geographies. That is to say, we can safely infer that in most cases lynch mobs were formed from the communities in which a crime or transgression is reported to have been committed. Datelines

Table B1. Distribution of Similarities at the County Level for Geographies Inferred from the Newspaper Accounts-Place of Mob Formation, the Alleged Crime or Transgression, Intervention, and Dateline

\begin{tabular}{lcccc}
\hline & Dateline & Intervention & Alleged crime & Mob formation \\
\hline Dateline & $100 \%$ & $57 \%$ & $52 \%$ & $38 \%$ \\
\hline Intervention & - & $100 \%$ & $85 \%$ & $59 \%$ \\
\hline Alleged crime & - & - & $100 \%$ & $73 \%$ \\
\hline Mob formation & - & - & - & $100 \%$ \\
\hline
\end{tabular}

Note: Cell percentages express the ratio of cases in which counties coincide in case both counties had been reported.

Table B2. Distribution of Similarities at the County Level for Geographies Inferred from the Newspaper Accounts-Place of Mob Formation, the Alleged Crime or Transgression, Intervention, and Dateline

\begin{tabular}{lcccc}
\hline & Dateline & Lynching & Alleged crime & Mob formation \\
\hline Dateline & $100 \%$ & $59 \%$ & $58 \%$ & $60 \%$ \\
\hline Lynching & - & $100 \%$ & $88 \%$ & $88 \%$ \\
\hline Alleged crime & - & - & $100 \%$ & $95 \%$ \\
\hline Mob formation & - & - & - & $100 \%$ \\
\hline
\end{tabular}

Note: Cell percentages express the ratio of cases in which counties coincide in case both counties had been reported. 
have more variability, especially in North Carolina, where news production seems to have been more centralized. Still, in most cases, datelines and reported events have concordance at the county level.

We constructed a geography for our events in the following way: (1) we noted settlements named in event narratives; then (2) geographically referenced these settlements with their (current) coordinates that come from two sources: in case of exact match on name, we inferred them from the Global Rural-Urban Mapping Project USA Settlement file ${ }^{15}$; in case of no exact matches (which occurred for populated places and settlements that no longer exist), we used Google Maps and additional research to turn up their geographic location.

Census data and vote share come at the county level. We distributed these data assuming uniform distribution. Based on this logic and carrying forward our example, if the 1880 counties A and B gave rise to county C, and county C's territory had been county A in 60 percent and county B in 40 percent, than the population of county $\mathrm{A}$ after $\mathrm{t} 2$ would be calculated based on (the remainder of) county A and 60 percent of the population of county C-county B's population would be calculated in a similar manner. The ratios that relate county-territories come from overlaying the county boundary files from different censuses and constructing a matrix that compares 1880-1890, 1880-1900, 1880-1910, $1880-1920$, and $1880-1930$ county boundaries, respectively. Cotton production volumes to the 1880 counties are attributed the same way as population. In case of vote shares, we first allocated numbers of votes cast for the different parties to the 1880 counties, then computed the ratios.

\section{Appendix C. Robustness Checks}

In this appendix, we report on some robustness checks. First, we replicate the same analysis presented in this paper using a different, more traditional allocation strategy: generating county clusters. Second, we report on results obtained from negative binomial models of count data at the 1880 county level for six-month periods that are generally consistent with our findings.

In figure $\mathrm{C} 1$, we present the map of county clusters. We shaded gray the clusters that contain between four and fourteen counties-denoted "monster clusters." Small clusters are patterned, either dotted or checked, so that one can distinguish them when they share a border. On an 1880 map, there are nine clusters in Georgia, five in Mississippi, and eleven in North Carolina. If one was to look at a 1930 map, Georgia would have eleven, Mississippi would have seven, and North Carolina fourteen clusters. The difference arises when an 1880 county splits in half, and the new county becomes visible from the time of its creation. As we pointed out previously, Georgia experienced the most important boundary changes over time. In North Carolina, very few new counties were created after 1880; frequently, however, two counties renegotiated their borders, reflected by the large number of small clusters.

The results from the analyses based on meaningful county clusters are reported in figure $\mathrm{C} 2$. The "monster clusters" are meaningless geopolitical units 
Figure C1. Map of county clusters in Georgia, Mississippi, and North Carolina based on 1880 maps

Georgia

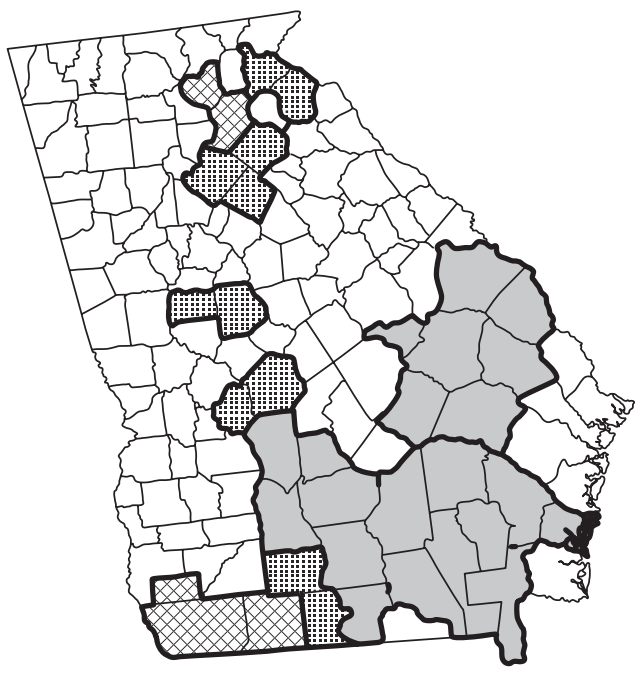

Mississippi

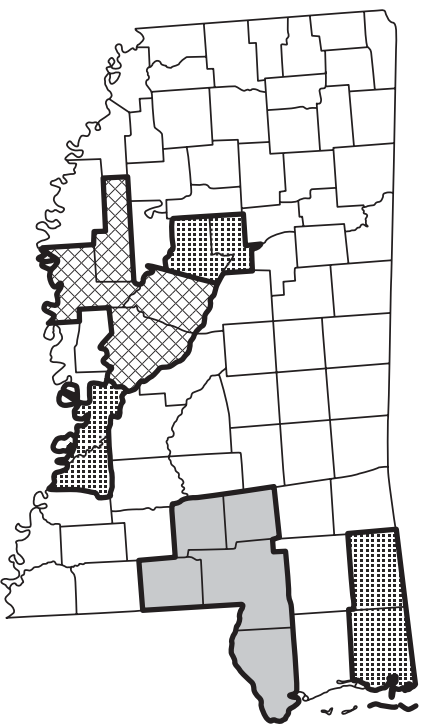

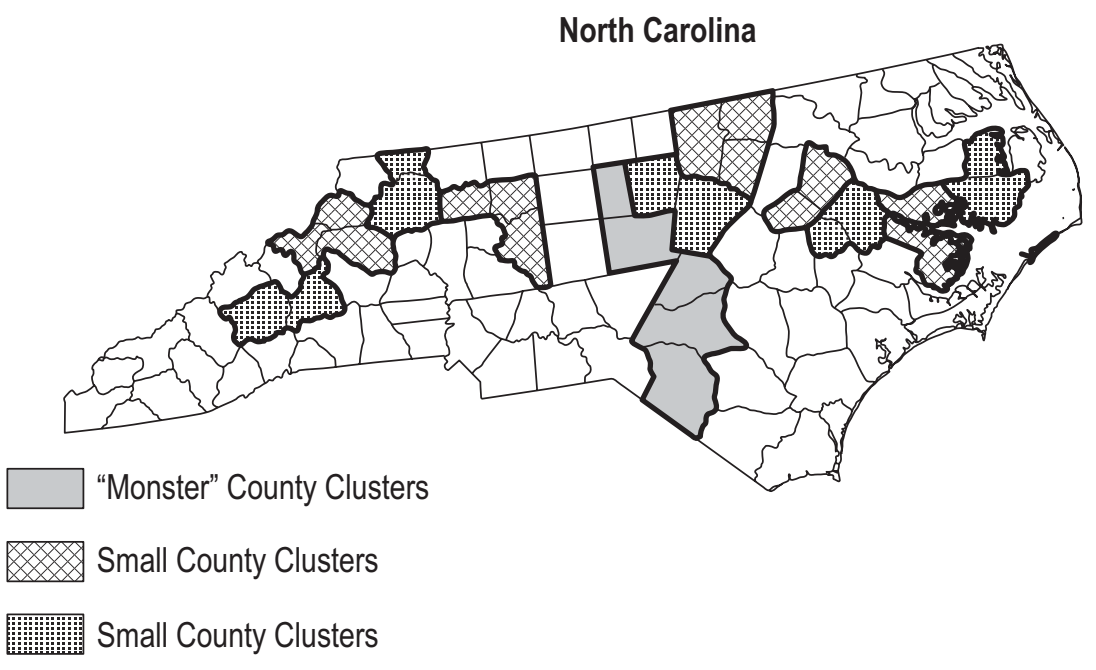

and were consequently removed from these analyses. We can see that the cluster strategy returns comparable results to the strategy we developed, although some statistical power is lost due to fewer observations.

We also ran negative binomial models where the dependent variable is the count of completed lynching, mob formation, and averted lynching events in a six-month interval (to reduce the number of observations, which make estimation feasible) using the glmmADMB package in $R$. All variables that we found to be significantly associated with completed lynching, mob formation, and 
Figure C2. Results from Cox proportional hazard models for completed lynching events, mob formation events, and averted lynching events using county clusters without the "monster clusters"
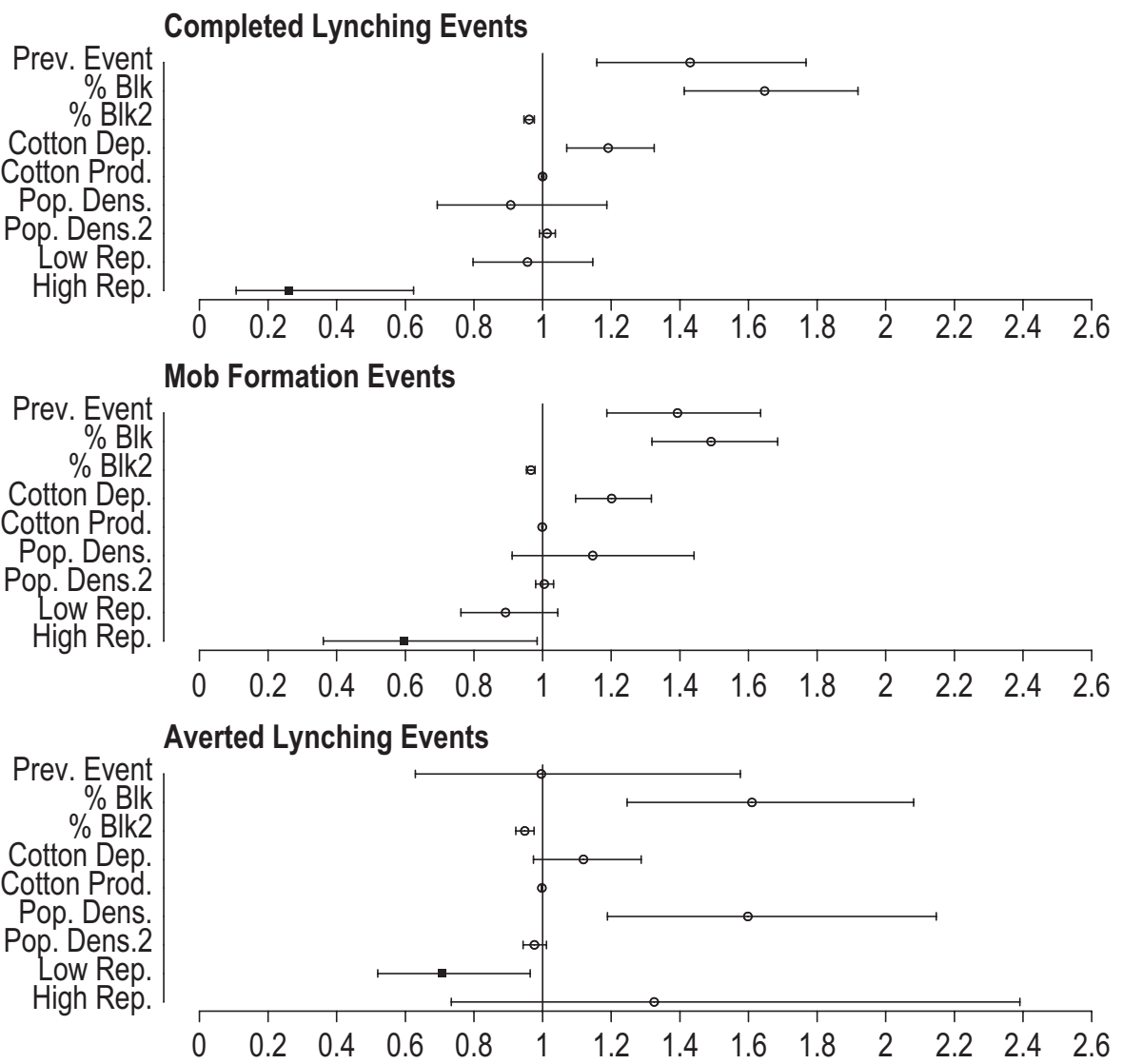

averted lynching events were significant in the negative binomial models as well, and coefficients agree in their direction and relative effect sizes.

One reviewer suggested that a fixed-effects specification might be more appropriate, but we do not agree. There is a simple reason to reject a fixed-effects framework: the assumptions required by this approach cannot be meaningfully met without fundamentally warping historical reality. In the case of omitted variables that are correlated with the variables in one's model, one worries about biased estimates of the coefficients. Under some conditions, a fixed-effects model provides a strategy for avoiding omitted-variable bias. The key condition is that the omitted variables one imagines as potentially biasing the estimates must have time-invariant values with time-invariant effects at the unit level. Thus, a fixedeffects specification implies a search across the South for a county-level characteristic (counties are the units in this case) that does not change in value or expression over a fifty-year period in a context where mobs composed of different people form, succeed, or fail in killing, and are stopped or ignored by different agents 
of the state, during an era of major social, political, and economic upheaval. For such a characteristic to exist, it would need to be passed down from generation to generation at the county level, express itself in irregular temporal patterns at most a handful of times, and be insensitive to changing demographics arising from in- and out-mobility. When thinking about individuals and their social action, a fixed-effects model makes some sense in that we can imagine a theoretically motivated individual-level characteristic that does not vary significantly over time and that may shape behavior; for example, their genome. That is of little use to us here. More substantively, a fixed-effects framework makes no sense in a study of historical dynamics in which, necessarily, the actions that men take shape the multiple social, political, economic, and value contexts in which their future, and future action, unfolds, and by so doing, changes as well the meaning of their shared past.

\section{References}

Ames, Jessie Daniel. 1942. The Changing Character of Lynching. Atlanta: Commission on Interracial Cooperation.

Ayers, Edward L. 1993. The Promise of the New South: Life after Reconstruction. Oxford, New York, Toronto: Oxford University Press.

Bailey, A. K., S. E. Tolnay, E. M. Beck, and J. D. Laird. 2011. “Targeting Lynch Victims: Social Marginality or Status Transgressions?" American Sociological Review 76(3):412-36.

Bailey, A. K., S. E. Tolnay, E. M. Beck, A. R. Roberts, and N. H. Wong. 2008. "Personalizing Lynch Victims: A New Database to Support the Study of Mob Violence." Historical Methods: A Journal of Quantitative and Interdisciplinary History 41(1):47-64.

Baller, R. D., L. Anselin, S. F. Messner, G. Deane, and D. F. Hawkins. 2001. "Structural Covariates of U.S. County Homicide Rates: Incorporating Spatial Effects." Criminology 39(3):561-88.

Beck, E. M., J. L. Massey, and S. E. Tolnay. 1989. "Gallows, the Mob, and the Vote: Lethal Sanctioning of Blacks in North Carolina and Georgia, 1882 to 1930." Law \& Society Review 23(2):317-31.

Beck, E. M., and S. E. Tolnay. 1990. "The Killing Fields of the Deep South: The Market for Cotton and the Lynching of Blacks, 1882-1930." American Sociological Review55(4):526-39.

Blalock, Hubert M. 1967. Toward a Theory of Minority-Group Relations. New York: Wiley.

Brundage, W. Fitzhugh. 1993. Lynching in the New South: Georgia and Virginia, 1880-1930. Urbana: University of Illinois Press.

1994. “The Varn Mill Riot of 1891: Lynchings, Attempted Lynchings, and Justice in Ware County, Georgia." Georgia Historical Quarterly 78(2):257-80.

Cleves, Mario, William Gould, Roberto G. Gutierrez, and Yulia V. Marchenko. 2002 [2010]. An Introduction to Survival Analysis Using Stata. College Station, TX: Stata Press.

Corzine, J., and J. Creech. 1983. "Black Concentration and Lynchings in the South: Testing Blalock's PowerThreat Hypothesis." Social Forces 61(3):774-96.

Cox, D. R. 1972. "Regression Models and Life Tables (with Discussion)." Journal of the Royal Statistical Society, Series B34:187-220.

Creech, J. C., J. Corzine, and L. Huff-Corzine. 1989. "Theory Testing and Lynching: Another Look at the Power Threat Hypothesis." Social Forces 67(3):626-30.

de la Roche, R. S. 1996. "Collective Violence as Social Control." Sociological Forum 11(1):97-128.

Earl, J., A. Martin, J. D. McCarthy, and S. A. Soule. 2004. "The Use of Newspaper Data in the Study of Collective Action." Annual Review of Sociology 30(1):65-80. 
Eitle, D., S. J. D’Allessio, and L. Stolzenberg. 2002. "Racial Threat and Social Control: A Test of the Political, Economic, and Threat of Black Crime Hypothesis." Social Forces 81(2):557-76.

Ellis, M. L. 1986. "A Lynching Averted: The Ordeal of John Miller." Georgia Historical Quarterly 70(2):306-16.

Foner, Eric. 1988. Reconstruction: America's Unfinished Revolution, 1863-1877. New York: Harper \& Row.

Franzosi, R. 1987. "The Press as a Source of Socio-Historical Data: Issues in the Methodology of Data Collection from Newspapers." Historical Methods 20:5-16.

Grambsch, P. M., and T. M. Therneau. 1994. "Proportional Hazard Tests and Diagnostics Based on Weighted Residuals." Biometrika 81:515-26.

Granovetter, M. 1978. "Threshold Models of Collective Behavior." American Journal of Sociology 83(6)::1420-43.

Green, D. P., J. Glaser, and A. Rich. 1998. “From Lynching to Gay Bashing: The Elusive Connection Between Economic Conditions and Hate Crime." Journal of Personality and Social Psychology 75(1):82-92.

Green, D. P., L. H. McFalls, and J. K. Smith. 2001. "Hate Crime: An Emergent Research Agenda." Annual Review of Sociology 27:479-504.

Griffin, L. J. 1993. "Narrative, Event-Structure Analysis, and Causal Interpretation in Historical Sociology." American Journal of Sociology 98(5):1094-133.

Griffin, L. J., C. Caplinger, K. J. Lively, N. L. Malcom, D. McDaniel, and C. Nelsen. 1997. "ComparativeHistorical Analysis and Scientific Inference: Disfranchisement in the U.S. South as a Test Case." Historical Methods: A Journal of Quantitative and Interdisciplinary History 30(1):13-27.

Gullickson, A. 2010. "Racial Boundary Formation at the Dawn of Jim Crow: The Determinants and Effects of Black/Mulatto Occupational Differences in the United States, 1880." American Journal of Sociology 116(1):187-231.

Gutmann, M. P., S. M. Pullum-Pinon, K. Witosko, G. D. Deane, and E. Merchant. 2012. "Land Use and Family Formation in the Settlement of the Great Plains." Social Science History 36(3):279-310.

Hargis, P. G. 1994. "In Quest of the Golden Fleece: African American Landholding in Georgia 1874-1933." $\mathrm{PhD}$ diss., University of Georgia.

Hepworth, Joseph T., and S. G. West. 1988. "Lynchings and the Economy: A Time-Series Reanalysis of Hovland and Sears (1940)." Journal of Personality and Social Psychology 55(2):239-47.

Inverarity, J. M. 1976. "Populism and Lynching in Louisiana, 1889-1896: A Test of Erikson's Theory of the Relationship between Boundary Crises and Repressive Justice." American Sociological Review 41(2):262-80.

Kousser, J. M. 1974. The Shaping of Southern Politics: Suffrage Restriction and the Establishment of the One-Party South, 1880-1910. New Haven, CT: Yale University Press.

Krueger, A., and J. S. Pischke. 1997. "A Statistical Analysis of Crime against Foreigners in Unified Germany." Journal of Human Resources 32(1):182-209.

Land, K. C., G. Deane, and J. R. Blau. 1991. "Religious Pluralism and Church Membership: A Spatial Diffusion Model." American Sociological Review56(2):237-49.

Messner, S. F., R. D. Baller, and M. P. Zevenbergen. 2005. “The Legacy of Lynching and Southern Homicide.” American Sociological Review 70(4):633-55.

Myers, D. J., and B. S. Caniglia. 2004. "All the Rioting That's Fit to Print: Selection Effects in National Newspaper Coverage of Civil Disorders, 1968-1969." American Sociological Review 69:519-54.

Olzak, S. 1990. "The Political Context of Competition: Lynching and Urban Racial Violence." Social Forces 69(2):395-421.

Ortiz, D. G., D. J. Myers, N. E. Walls, and M. D. Diaz. 2005. "Where Do We Stand with Newspaper Data?" Mobilization: An International Journal 10:397-419.

Phillips, D. P. 1987. "Exploring Relations among Forms of Social Control: The Lynching and Execution of Blacks in North Carolina, 1889-1918." Law \& Society Review 21(3):361-74. 
Platt, J. 1981. "Evidence and Proof in Documentary Research: 1: Some Specific Problems of Documentary Research." Sociological Review 29(1):31-52.

Prentice, R. L., B. J. Williams, and A. V. Peterson. 1981. “On the Regression Analysis of Multivariate Failure Time Data." Biometrika 68:373-79.

Raper, Arthur F. 1933. The Tragedy of Lynching. Chapel Hill: University of North Carolina Press.

Redding, Kent. 2003. Making Race, Making Power: North Carolina's Road to Disenfranchisement. Urbana: University of Illinois Press.

Reed, J. S. 1972. "Percent Black and Lynching: A Test of Blalock's Theory." Social Forces 50(3):356-60.

Schwartz, M. 1976. Radical Protest and Social Structure: The Southern Farmers' Alliance and Cotton Tenancy, 1880-1890. Chicago: University of Chicago Press.

Snyder, D., and C. Tilly. 1972. "Hardship and Collective Violence in France, 1830 to 1960."American Sociological Review 37(5):520-32.

Soule, S. A. 1992. "Populism and Black Lynching in Georgia, 1890-1900." Social Forces 71(2):431-49.

Stovel, K. 2001. "Local Sequential Patterns: The Structure of Lynching in the Deep South, 1882-1930." Social Forces 79(3):843-80.

Tolnay, Stewart E., and E. M. Beck. 1995a. A Festival of Violence-An Analysis of Southern Lynchings, 1882-1930. Urbana and Chicago: University of Illinois Press.

1995b. "Racial Violence and Black Migration in the American South, 1910 to 1930." American Sociological Review 57(1):103-16.

Tolnay, S. E., G. Deane, and E. M. Beck. 1996. "Vicarious Violence: Spatial Effects on Southern Lynchings, 1890-1919." American Journal of Sociology 102(3):788-815. 